\title{
Perforator-based Reverse Radial Teno-Adipo-Fascial Flap: Surgical Technique and Case-report for the Functional Reconstruction of the Dorsum of the Hand
}

\author{
Reverse Radialis Teno-Adipo-Fasziale Lappenplastik basierte auf \\ Perforans-Gefäßen: chirurgische Technik und Case-report der \\ funktionellen Rekonstruktion des Handrückens (Dorsum manus)
}

Autoren

Andrea Raspanti ${ }^{1}$, Andrea Poggetti ${ }^{2}$, Serena Ghezzi ${ }^{3}$, Luca Delcroix ${ }^{4}$, Carla Baldrighi ${ }^{4}$, Marco Innocenti ${ }^{4}$

Affiliations

1 Azienda UsI Toscana Centro, Department of Surgery - Orthopedic and Traumatology, Firenze, Italy

2 Azienda Ospedaliero Universitaria Careggi, Hand and Reconstructive Microsurgery Unit, Firenze, Italy

3 Azienda Ospedaliero Universitaria Careggi, Plastic Surgery and Reconstructive Microsurgery, Firenze, Italy

4 University Hospital Careggi CTO, Plastic reconstructive surgery and microsurgery - Oncology, Firenze, Italy

Schlüsselwörter

Rekonstruktion des Handrückens (Dorsum manus), vaskularisierte Sehnentransplantation, retrograde radiale Lappenplastik, adipo-fasziale Lappenplastik, funktionelle Rekonstruktion

Key words

dorsal hand reconstruction, vascularized tendon graft, reverse radial flap, adipofascial flap, functional reconstruction

received $\quad 04.03 .2019$

accepted 13.03.2019

Bibliografie

DOI https://doi.org/10.1055/a-0881-9835

Handchir Mikrochir Plast Chir 2019; 51: 464-468

(c) Georg Thieme Verlag KG Stuttgart · New York

ISSN 0722-1819

Correspondence Adress

Dr. Andrea Raspanti

Azienda UsI Toscana Centro,

Department of Surgery - Orthopedic and Traumatology

Piazza Santa Maria Nuova, 1 (registered office)

50122 Firenze

Tel.: + 39055693611

Fax: + 39055693611

E-Mail: andrea.raspanti@live.it
ABSTRACT

Background Dorsal complex cutaneotendinous lesions of the hand represent a reconstructive challenge. The use of composite microvascular flaps and vascularized tendon grafts represent the gold-standard. The radial anti-brachial region can still represent an excellent donor site, to the detriment of the possible sacrifice of the radial artery. The reverse radial anti-brachial flap can be either perforator-based, thus saving the radial artery or raised as an adipo-fascial flap, to spare the skin.

Patients and Methods A case of post-traumatic highly contaminated dorsal cutaneotendinous defect of the second ray of the hand was reported. An original surgical reconstructive technique with a Revers Radial Teno-Adipo-Fascial Flap (RRTAFF) plus vascularized Palmaris Longus was described, preserving the radial artery. A simple partial thickness skin graft was performed a second time to complete dorsal cutaneous coverage. A subsequent infection was managed by trusting the complete vascularization of the tissues used for the reconstruction.

Results The hand healed well with containment of the infection. The dorsal healed skin appeared elastic and pliable enough. Passive and active motion of interphalangeal and metacarpofalangeal joints were very satisfying. The donor site was well healed, with almost no morbidity.

Conclusions This reconstructive strategy provides a quick and straightforward single-stage option for the reconstruction of complex cutaneotendinous defects of the dorsum of the hand. Such a reconstruction, with a completely vascularized procedure, is particularly indicated in cases of high contamination or infection of the recipient site.

\section{ZUSAMMENFASSUNG}

Hintergrund Komplexe tendokutane Läsionen des Handrückens stellen eine Herausforderung der funktionellen Rekonstruktion dar. Die mikrovaskularisierten composite-Lappenplastiken und vaskularisierten Sehnentransplantationen stellen den Goldstandard dar. Der beugeseitige Unterarm dienst als exzellente Entnahmestelle, trotz der potentiellen Gefahr eines Verlustes der A. radialis. Der reverse radial anti-brachial flap kann unter Schonung der A. radialis als Perforatorlappenplastik 
gehoben werden, ebenso als adipofaszialer Lappen unter Einsparung der Haut.

Patienten und Methoden Wir berichten über den Fall eines posttraumatischen, stark kontaminierten Weichteilschadens des rechten Handrückens mit Sehnenbeteiligung auf Höhe des zweiten Mittelhandknochens. Wir beschreiben das rekonstruktive Verfahren mit der Reverse Radial Teno-Adipo-Fascial Lappenplastik (RRTAF-Flap) und einem vaskularisierten Palmaris Longus Lappen unter Erhalt der A. radialis. Im Verlauf führten wir eine Spalthauttransplantation zur Deckung des übrigen Weichteildefektes durch. Die gute Vaskularisierung des Transplantatates inklusive der Sehne kann Wundinfekten und Transplantatverlusten, insbesondere bei kontaminierten Befunden, vorbeugen.
Ergebnisse Die transplantierte Haut zeigte sich nach vollständiger Abheilung elastisch und stabil. Die aktive und passive Beweglichkeit im Metacarpophalangealgelenk und in den Interphalangealgelenken entwickelte sich postoperativ sehr zufriedenstellend. Die Entnahmestelle heilte ohne Komplikationen und mit keiner Morbidität.

Schlussfolgerung Diese Rekonstruktionsstrategie bietet eine prompte und direkte single-stage Alternative für die Defektdeckung und Rekonstruktion bei komplexen Handrückendefekten. Solche Rekonstruktion ist für die Defektdeckung und Rekonstruktion bei komplexen Handrückendefekten. Ein solches vaskularisiertes Transplantat ist insbesondere im Falle einer Kontamination oder Infektion vorteilhaft.

\section{Introduction}

Dorsal complex teno-cutaneous lesions of the hand represent a reconstructive challenge concerning modalities, times, need of early mobilization and often invalidating outcomes. The usage of composite microvascular flaps and vascularized tendon grafts is currently the gold-standard for this type of reconstruction, especially in case of large defects and/or in the presence of contamination/ infection. In this context, the radial anti-brachial region, due to its quality, proximity and also thanks to the presence of sacrificial tendons, can still represent an excellent donor site. To overcome the possible sacrifice of the radial artery, nonetheless, the reverse radial anti-brachial flap can be based on the perforator arteries. Moreover, the flap can be raised as an adipo-fascial, thus saving the skin. The reverse radial forearm flap, as either a fascial flap or a fasciocutaneous flap, has been extensively used for the hand coverage in distal soft-tissue reconstruction [1-4]. The traditional flap consists of a single stage procedure that provides well-perfused tissue to the palm, dorsum, or thumb-index web space. It incorporates the radial artery from the forearm and is perfused by retrograde flow through the palmar arch. Weinzweig et al. [5] and Jeng and Wei [6] demonstrated the use of reverse radial forearm fasciosubcutaneous flap without radial artery sacrifice, basing the flap on radial artery perforators. This approach has beneficial implications for patients with incomplete palmar arches. A clinical case was reported, in which the "Chinese" flap based on radial artery perforators was used for dorsal hand coverage. In a post-traumatic highly contaminated dorsal cutaneotendinous defect of the second ray of the hand, the reconstruction technique with a Revers Radial Teno-Adipo-Fascial Flap (RRTAFF) plus vascularized Palmaris Longus (PL) tendon, based on radial artery distal perforators, was described. Its clinical application provides a quick and straightforward single-stage option for the reconstruction of complex cutaneotendinous defects of the hand, without the sacrifice of the radial artery.

\section{Patients and Methods}

A case of highly contaminated post-traumatic loss of tissue of the dorsal hand, in a 77-year-old patient, was reported. The defect ex-

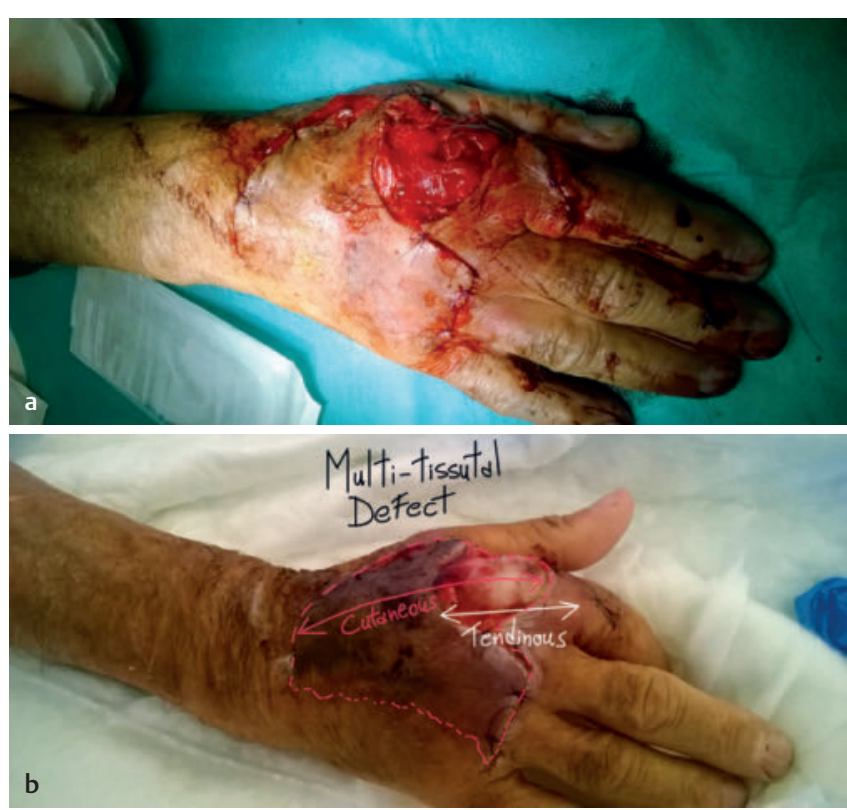

- Fig. 1 Right hand. a Highly contaminated post-traumatic loss of tissue of the back of the hand, in a 77-year-old patient after preliminary treatment at the emergency room. b After washing and debridement we can observe the real loss of tissues extended from the $1^{\text {st }}$ commissure to the $3^{\text {rd }}$ metacarpus, with a tendon gap of the Extensor Digitorum Communis (EDC) for the $2^{\text {nd }}$ and Extensor Indicis Proprius (EIP) (from zone 4 to 6 ) and with exposure of the $2^{\text {nd }}$ metacarpophalangeal (MCF) joint.

tended from the $1^{\text {st }}$ commissure to the $3^{\text {rd }}$ metacarpus, with a tendon gap of the Extensor Digitorum Communis (EDC) for the 2nd and Extensor Indicis Proprius (EIP) (from zone 4 to 6 ) and with exposure of the $2^{\text {nd }}$ metacarpophalangeal (MCF) joint ( $>$ Fig. 1 b). The patient came to our attention for a "second-look", after immediate treatment of simple washing, debridement and partial closure ( $>$ Fig. 1a, $>$ Fig. 1 b). The radical debridement was completed keeping only the skin still with uncertain vascularization. The radial anti-brachial flap was harvested as adipo-fascial plus vascularized tendon of Palmaris Longus (PL), pedicled with reverse flow, based 


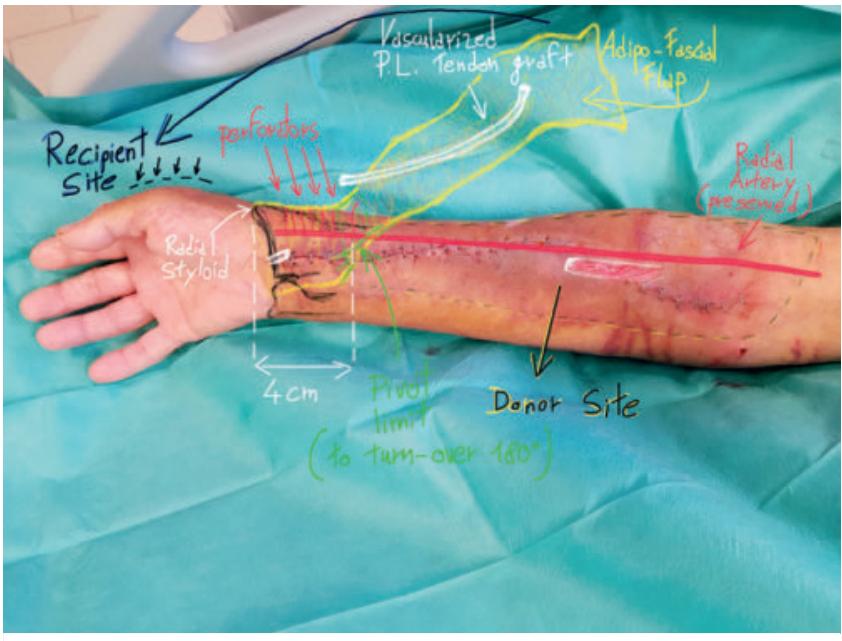

- Fig.2 Right forearm. Diagram of the raised pedicled flap to cover the defect on the back of the hand: Revers Radial Teno-Adipo-Fascial Flap (RRTAFF) plus vascularized Palmaris Longus (PL), based on radial artery distal perforators.

on the perforators, thus saving the radial artery: Perforator-based Reverse Radial Teno-Adipo-Fascial Flap (RRTAFF).

\section{Operative Technique}

The RRTAFF was performed with the patient supine and a tourniquet in place on the upper arm. The forearm was placed on a table, fully supinated, after the complete debridement of necrotic and contaminated soft tissues of the dorsal aspect of the hand. The tourniquet was then inflated. The flap was raised following the preoperative drawing, respecting the defect size. A curved incision was made from the wrist to the antecubital fossa. The incised skin was undermined and separated from the underlying adipofascial tissue. The adipofascial island was centered along the axis of the radial artery, extending proximally to the antecubital fossa with a distal pivot point $4 \mathrm{~cm}$ proximal to the radial styloid ( $\triangleright$ Fig. 2 ). Loupes magnification was thus necessary. The flap was raised ulnarward in the subfascial plane. The lateral antebrachial cutaneous nerve was preserved. The radial artery was spared and its perforators for the flap at the level of the pivot were protected. During the harvest great attention was paid in preserving the fascia surrounding the $\mathrm{PL}$ tendon. Therefore, the fascia was raised starting from a more ulnar side and so antebrachial fascia and PL tendon, which was contained in a doubling of the fascia, were harvested together in a single layer ( $\triangleright$ Fig. 2). This guaranteed a physiological gliding channel for the tendon and preserved its blood supply. Then this composite flap was completely raised and rotated $180^{\circ}$ to check the correct coverage of the defect in the hand. The flap was transposed to the defect using a subcutaneous tunnel. Then the tenorrhaphy and the intercalary reconstruction of the $2^{\circ} \mathrm{EDC}$ and EIP was performed, using $\mathrm{PL}$ and looping it distally (at the level of F1) and simply suturing it proximally in termino-terminal way ( $\mathbf{F i g . 3 b}$ ). The donor site was closed primarily. A suction drain was used for one day.

At the end the tendon graft restored a correct $2^{\text {nd }}$ finger "cascade", in harmony with the other fingers and the flap was well vascularized ( $\vee$ Fig. 3a). Throughout the following days the reconstruc-
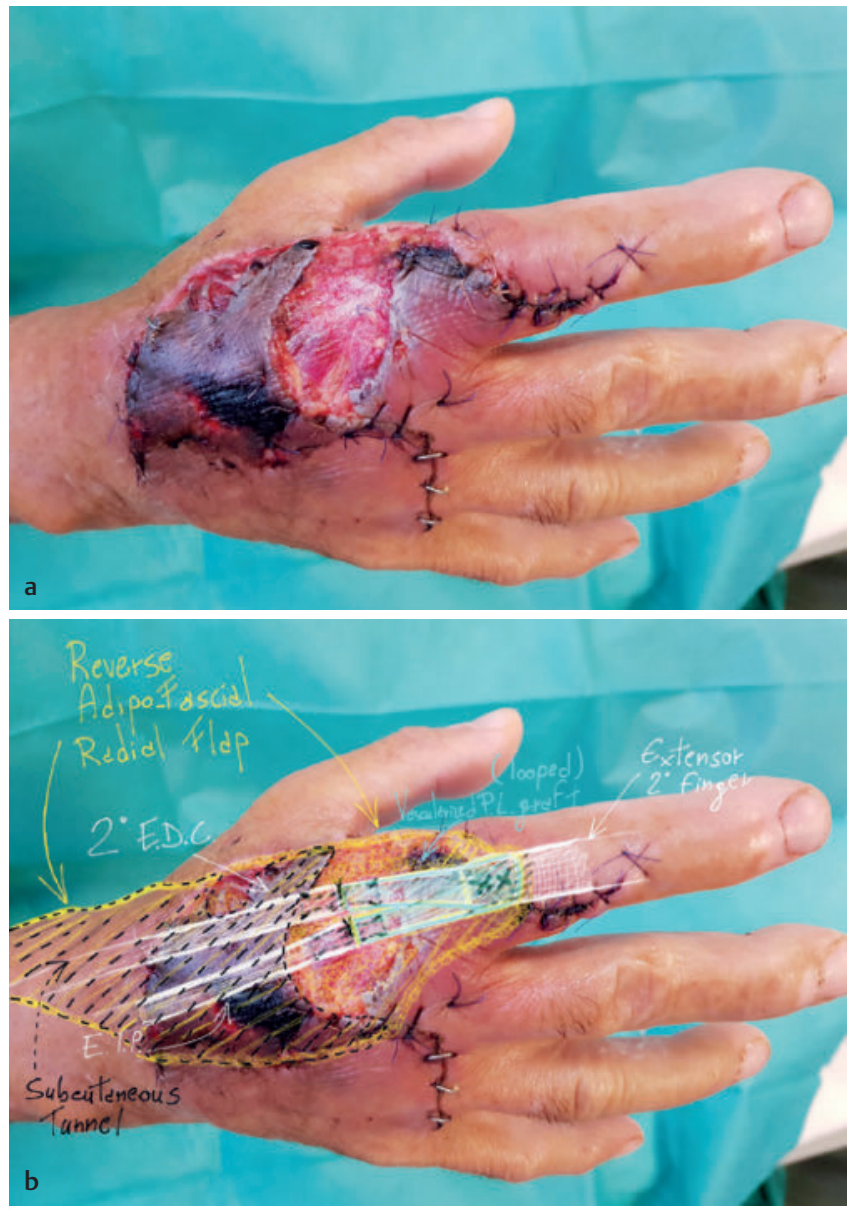

Fig. 3 Right hand. a Final result after covering the recipient site with the flap (evident vascularized tissue under partially necrotic skin and over the reconstructed tendons). See also the restoration of extension of the second finger. $\mathbf{b}$ Diagram of the reconstructed area with the adipofascial flap and the looped vascularized Palmaris Longus (PL) tendon graft for $2^{\text {nd }}$ Extensor Digitorum Communis (EDC) and Extensor Indicis Proprius (EIP).

tion appeared stable and vital, with further necrotic demarcation in the spared dorsal skin, ulnarward. Then, a new surgery was planned for the definitive removal of necrotic or non-reliable skin and partial thickness demo-epidermic grafting ( $>$ Fig. 4a, $\triangleright$ Fig. 4b).

\section{Results}

At the first dressing, the dermoepidermal graft was partially engrafted. Subsequent checks revealed non-rooted areas and signs of superficial infection. However, advanced dressings and standard antibiotic prophylaxis were continued after performing a simple washing and superficial remediation of the biofilm and potentially infected areas. After 2 weeks the cleaning of a fibrin bed showed tendon exposure (reconstruction of the extensor apparatus of the $2^{\text {nd }}$ ray with vascularized tendon graft of $\mathrm{PL}$ ) proximal to the MCF joint. An empirical antibiotic therapy (amoxicillin/clavulanate $875 / 125 \mathrm{mg}: 1 \times 3 /$ die) was decided upon and to continue with advanced dressings on a weekly basis, reaching the complete coverage of the defect and re-epithelization within 3 weeks ( $\triangleright$ Fig. 4c). Then the hand was well healed without signs of infection. The dor- 


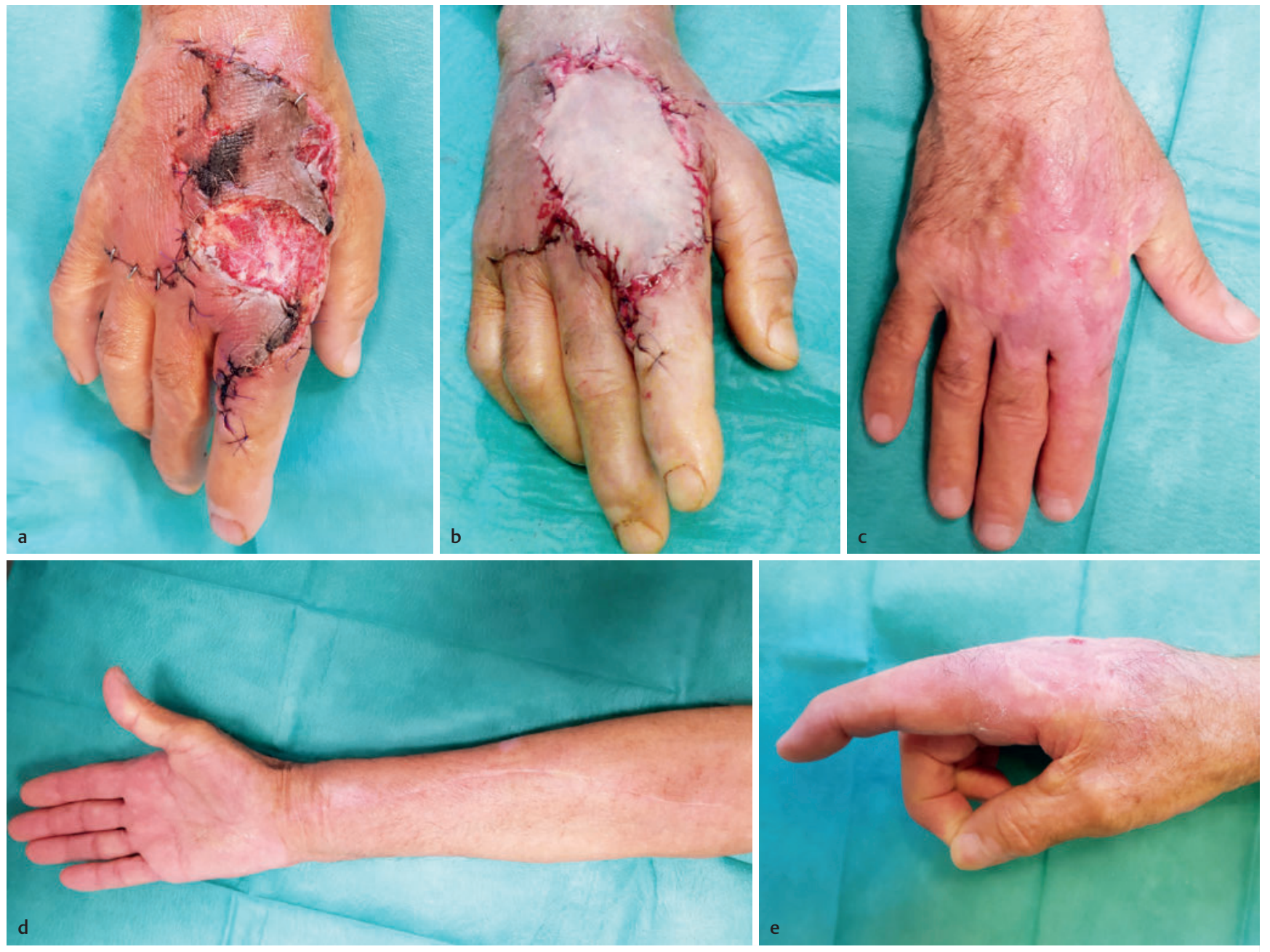

- Fig. 4 Right hand. Clinical progression: $\mathbf{a}$ after the first operation, $\mathbf{b}$ after further debridement and skin grafting, $\mathbf{c}$ and after the subsequent advanced dressings. $\mathbf{d}$ Donor site final result. e Functional result of the $2^{\text {nd }}$ finger with active motion in extension.

sal skin appeared elastic and pliable enough. The donor site was well healed and with almost no morbidity ( $\bullet$ Fig. 4d). The forearm and the hand were protected with a plaster splint in "safe position" for 3 weeks. After this period a rehabilitation program started and only dressings and bandages were applied. Passive (P-ROM) and active (A-ROM) range of motion of interphalangeal (IF) and MCF joints were very satisfying: see P-ROM and A-ROM ( $\vee$ Fig. 4 , $\triangleright$ Video).

\section{Discussion}

The traditional "Chinese" flap was used extensively in reconstructive hand surgery [1-4]. Jet Weinzweig et al., in 1994, and Jeng and Wei, in 1998, [5, 6] described a technique preserving the radial artery, basing the flap on perforators. In 1983, Reid and Moss [7] reported a modification of the radial artery forearm flap for one-stage repair of dorsal hand injuries: they harvested the Palmaris Longus $(\mathrm{PL})$ and a portion of the Brachioradialis (BR) tendon along with fascia and skin. In 1996, Yajima et al [8] described a series of cases with soft-tissue defects of the hand: they treated them using a cutaneotendinous radial forearm flap, augmented with the PL tendon and Flexor Carpi Radialis (FCR) tendon. More recently, the "Chinese" flap was used as cutaneotendinous free flap, for the reconstruction

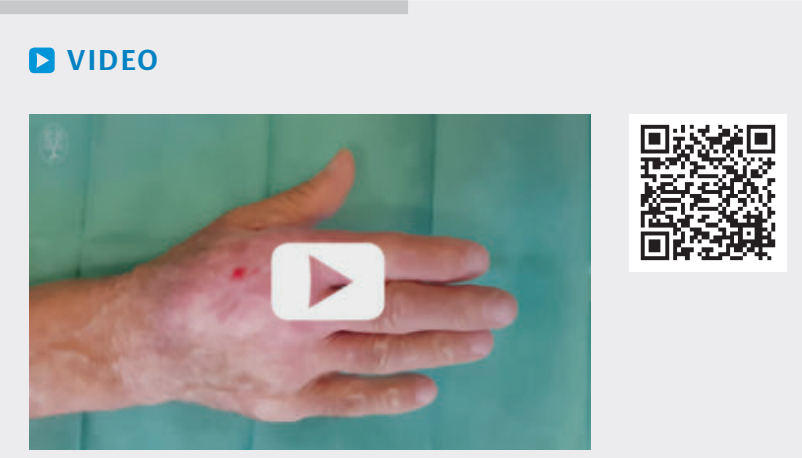

-Video 1 Right hand. Aesthetic and Functional results: good active range of motion and valid reconstruction of soft tissues and extensor apparatus (2nd EDC and EIP).

of multi-tissular distant defects. For example in 2015, Innocenti et al [9] reported a series of functional reconstructions of the Achilles region with a composite Chinese flap plus vascularized FCR tendon. While the following year, in 2016, Raspanti et al [10] published an 
anatomical study which described the vascularization of FCR tendon when included in the radial forearm flap.

In the present technical note the adipofascial style, the preservation of radial artery (perforator-based) and the inclusion of vascularized tendon grafts are all combined. The residual defect with secondary tendon exposure resulted in subsequent infectious complications (after the skin graft) was conservatively treated. This was possible given the small size of the defect. Nonetheless, the fact that we were dealing with all potentially vascularized tissue (and not with a simple tendon graft) allowed us to go down this path more safely and to successfully complete the procedure. On the contrary, the granulation tissue would have had difficulty in covering a devascularized tendon and deprived of its sheath, therefore a simple tendon graft managed to favor the spread of a deep infection.

\section{CONCLUSIONS}

The development of the classic "Chinese" flap guaranteed a quick and reliable operation for the reconstruction of complex lesions. Preservation of the radial artery and the forearm skin has transformed it in a less-invasive procedure. While the use of composite flaps has enriched the functional outcoming and reduced the reconstructive times. Our Operative Technique offers an adipofascial harvesting with skin preservation, a perforator-based flap with radial artery saving, and the inclusion of vascularized tendon grafts. Microsurgical dissection with high magnification is necessary, but anastomosis time is saved. Its clinical application provides a quick and straightforward single-stage all-vascularized option for the functional reconstruction of complex cutaneotendinous defects of the dorsum of the hand, particularly indicated in cases of high contamination or infection.

\section{Conflict of interest}

The authors declare that they have no conflict of interest.

\section{Acknowledgments}

We wish to thank Dr. Neri Lombardi and Dr. Sara Calabrese, colleagues and friends, for their invaluable help in translating part of the manuscript.
Authors

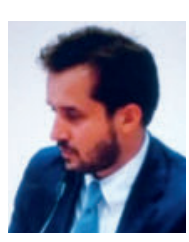

\section{Andrea Raspanti}

graduated in Medicine and Surgery with full marks and honors in July 2009.

I specialized in Orthopedics and Traumatology with full marks and honors in May 2015.

I spent my residency at the Careggi Hospital of Florence. I have perfected myself in the fields of hand surgery and reconstructive microsurgery through national and foreign advanced courses. I have published many scientific works in these fields. I graduated with merit to the only Italian Advanced Microsurgery Course, sponsored by SIM, SICM and SICPRE, and I was selected to be a Tutor.

I have always had productive relationships with SICM and SIM, participating in conferences, symposia and official courses of the Italian societies.

I am permanent medical manager for the Hospital AUSL Toscana Centro, based in Florence. I continue to work with the Reconstructive Plastic Surgery and Microsurgery Department of the Careggi Hospital.

\section{References}

[1] Chang SM, Hou CL. The development of the distally based radial forearm flap in hand reconstruction with preservation of the radial artery. Plast Reconstr Surg. 2000;106:955-7

[2] Dogan T, Gurunluoglu R, Imer B et al. The distally based forearm island flap in hand reconstruction. Plast Reconstr Surg. 1999;104:1581-2

[3] Martin D, Bakhach J, Casoli V et al. Reconstruction of the hand with forearm island flaps. Clin Plast Surg. 1997;24:33-48

[4] Koshima I, Moriguchi T, Etoh $\mathrm{H}$ et al. The radial artery perforator-based adipofascial flap for dorsal hand coverage. Ann Plast Surg. 1995;35:474-9

[5] Weinzweig N, Chen L, Chen ZW. The distally based radial forearm fasciosubcutaneous flap with preservation of the radial artery: an anatomic and clinical approach. Plast Reconstr Surg. 1994;94:675-84

[6] Jeng SF, Wei FC. The distally based forearm island flap in hand reconstruction. Plast Reconstr Surg. 1998;102:400-6

[7] Reid CD, Moss LH. One-stage flap repair with vascularized tendon grafts in a dorsal hand injury using the "Chinese" forearm flap. $\mathrm{Br}$ J Plast Surg. 1983;36:473-9

[8] Yajima $\mathrm{H}$, Inada $\mathrm{Y}$, Shono $\mathrm{M}$ et al. Radial forearm flap with vascularized tendons for hand reconstruction. Plast Reconstr Surg. 1996;98:328-33

[9] Innocenti M, Tani M, Carulli C et al. Radial forearm flap plus flexor carpi radialis tendon in Achilles tendon reconstruction: surgical technique, functional results, and gait analysis. Microsurgery. 2015;35:608-614

[10] Raspanti A, Delcroix L, Ghezzi S et al. Study of the tendinous vascularization for the compound radial forearm flap plus flexor carpi radialis tendon. Surg Radiol Anat. 2016;38:409-14 